\title{
LAS INSTITUCIONES CIENTÍFICAS \\ Y LA SOCIEDAD ABIERTA EN TELÉPOLIS
}

Javier Echeverria Departamento de Lógica y Filosofía de la Ciencia Universidad del País Vasco

1 Popper y la sociedad global.

En su célebre obra La sociedad abierta y sus enemigos $(S A)^{1}$, Popper contrapuso las sociedades cerradas y abiertas de la manera siguiente:

"seguiremos llamando sociedad cerrada a la sociedad mágica, tribal o colectivista, y sociedad abierta a aquella en que los individuos deben adoptar decisiones personales" 2 .

Las tesis popperianas sobre la sociedad, desarrolladas en este libro y en La miseria del historicismo $(M H)^{3}$, han sido ampliamente debatidas, y no es mi objetivo retomar aquí esa controversia. Sin embargo, en un párrafo del capítulo 10 de $S A$, poco después de la cita precedente, Popper expone una forma de sociedad abierta que tiene particular interés para el debate actual sobre las telecomunicaciones y la sociedad de la información, motivo por el cual merece la pena recordar este pasaje popperiano, muy poco comentado. Para Popper,

'. K.R. Popper, La sociedad abierta y sus enemigos, escrito de 1938 a 1943, publicado en 1950, trad. española en Buenos Aires, Paidós, 1982.

2. Ibid., p. 171.

${ }^{3}$ La miseria del historicismo (escrito en 1935 y publicado en Economica, 42, 43 y 46 en 1944-45), trad. española en Madrid, Taurus-Alianza 1987).

Éndoxa: Series Filosoficas, n゚ 5, 1995, UNED, Madrid:

Javier Echeverría: Las instituciones científicas y la sociedad abierta en Telépolis pp. 35-49. 
"No es imposible concebir una sociedad en que los hombres no se encontrasen nunca, prácticamente, cara a cara; donde todos los negocios fuesen llevados a cabo por individuos aislados que se comunicasen telefónica o telegráficamente y que se trasladasen de un punto a otro en automóviles herméticos. (La inseminación artificial permitiría, incluso, llevar a cabo la procreación sin elemento personal alguno). Podríamos decir de esta sociedad ficticia que es una "sociedad completamente abstracta o despersonalizada". Pues bien, lo interesante es que nuestra sociedad moderna se parece, en muchos de sus aspectos, a esta sociedad completamente abstracta" ... "Claro está que nuestro cuadro sigue siendo completamente exagerado. Nunca habrá ni podrá haber una sociedad completamente abstracta o siquiera preferentemente abstracta, así como no puede existir una sociedad completa o preferentemente racional" ${ }^{4}$.

En la época en que se escribió este texto, no existian la televisión, las redes telemáticas ni el dinero electrónico. Sin embargo, Popper afirmó la posibilidad teorica de una estructura social basada en individuos separados físicamente e intercomunicados a distancia. Una sociedad de este tipo podria ser una sociedad abierta en el sentido popperiano, precisamente porque en ella las instancias decisoras y actuantes serían estrictamente individuales: y aun cuando, según Popper, su propuesta fuera una simple ficción, ello no impedía que las sociedades modernas se orientaran en esa dirección. El pasaje precedente parece sugerir incluso que una sociedad completa o preferentemente racional se parecerfa bastante a esa "sociedad abstracta", cuyos miembros estarían comunicados a distancia por medio de diversas tecnologías.

El decurso ulterior de los países tecnologicamente avanzados ha venido a dar parcialmente la razón a esas premoniciones. Las redes telemáticas tipo Internet no sólo son indispensables para el desarrollo de la investigación científica mediante los servicios de acceso remoto o de transferencia de documentación y bases de datos, sino que prefiguran un nuevo modo de interacción social, basado en las relaciones humanas a distancia. Desde

\footnotetext{
4. Ibid., pp. 171-172.
} 
que McLuhan habló de la aldea global (global village) y Martin de la sociedad interconectada (wired society), se ha seguido avanzando en este sentido $^{5}$. Por mi parte, recientemente he llegado a afirmar que:

"durante el siglo XX se ha ido generando una nueva forma de organización social que tiende a expandirse por todo el planeta, transformándolo en una nueva ciudad: Telépolis" ... "Telépolis existe en la medida en que los ciudadanos se interrelacionan a distancia, bien sea directa 0 indirectamente" ${ }^{6}$.

A diferencia de las formas tribales de convivencia, basadas en el principio de territorialidad y de vecindad, las redes telemáticas y las tecnologías de las telecomunicaciones posibilitan en la actualidad unas relaciones humanas a distancia, y lo seguirán haciendo con mayor intensidad en el futuro inmediato. Todo ello ha dado lugar a la aparición de una nueva forma de sociedad abierta, que se adecúa en cierta medida a lo anticipado por Popper.

Las personas siguen viviendo en sus domicilios y pueden conectarse o no a las redes mundiales. Hoy en día, las redes telemáticas llegan a un porcentaje ínfimo de viviendas: la mayor parte de las conexiones a estas redes (Internet, Milnet, Swift, etc.) tienen lugar desde las instituciones y las empresas. Sin embargo, gran parte de las profesiones se están adaptando rápidamente a este nuevo escenario de interacción social, que trasciende las fronteras y conlleva una nueva forma de cosmopolitismo 7

En el presente artículo, escrito con ocasion de un número con intención de rendir homenaje a Karl Popper tras su reciente fallecimiento (1994), me centraré exclusivamente en el impacto que tiene esta nueva forma de organización social sobre la actividad cientifica, y en particular sobre las instituciones cientfficas que la sustentan.

\footnotetext{
'. Véase M. McLuhan, Understanding Media, New York, McGraw Hill, 1965, ed. ampliada, asi como J. Martin, The Wired Society, Prentice-Hall, 1978, trad. española en Madrid, Tecnos, 1980.

6. J. Echeverría, Telépolis, Barcelona, Destino, 1994, pp. 11-12.

7. Ver J. Echeverria, Cosmopolitas domésticos, Barcelona, Anagrama, 1995.
} 


\section{2.- Internet y la sociedad abierta.}

En la conferencia Networld +Interop celebrada en Tokyo a finales de julio de 1994, el Director Ejecutivo de la Internet Society, Anthony-Michael Rukowski, vinculo las ideas popperianas de una sociedad abierta al actual funcionamiento de Internet, afirmando que:

"Ásí como Internet es tecnologicamente una matriz virual que permitiría conectar un máximo de 4.000 millones de ordenadores, cada uno de los cuales podría tener 64.000 puertos, es también una matriz que enlaza 20 a 30 millones de personas que, directa o indirectamente, utilizan esos ordenadores y procesos. Es una capacidad impresionante que permite la creación, casi instantánea, de grupos de trabajo, grupos de discusión y audiencias de todo tipo. Esa capacidad transciende las diferencias horarias por zonas en el planeta, las fronteras nacionales e institucionales y, en un futuro próximo, incluso las lenguas. En su extrapolación última es la sociedad abierta en la que cualquiera, en cualquier parte, puede ofrecer $o$ recibir cualquier información de cualquier otro en cuestión de segundos" 8 .

Desde la perspectiva de Rukowski, Internet se caracteriza por las siguientes peculiaridades:

" 1.- Creación de una infraestructura de información de abajo a arriba.

2.- Una solida malla a nivel mundial para conectar directamente billones de ordenadores y miles de procesos informáticos en cualquier plataforma informática y de telecomunicaciones que exista en cualquier parte del mundo.

3.- Un medio para la colaboración abierta en el enorme desarrollo y evolución de nuevas tecnologías y aplicaciones.

4.- La transformación de la estructura, métodos y capacidades individuales en todo tipo de empresas, instituciones y profesiones.

B. Boletín Informativo UDT, 26 (1995), P. 9. 
5.- Un mercado amplio y de crecimiento rapidísimo para servicios y productos relacionados con Internet" 9 .

Internet es una estructura abierta y está en plena expansión. A ella se han ido conectando otras muchas redes especificas (BITNET, Fido Net, AppleLink, Minitel, CompuServe, AT\&T mail, etc.), y nada impide que cualquier empresa $o$ institución cree su propia red telemática y la mantenga separada, conectada o en la periferia de Internet. La función principal de esta red de redes es garantizar la interconectividad entre redes, siendo cada una de éstas considerablemente autónoma. Cabe afirmar que Internet es una estructura estrictamente federal, y en ese sentido no tiene precedente como germen de una ciudad electrónica global (ayuntamiento de redes). Los más diversos oficios y profesiones utilizan sus servicios y es previsible que en los próximos años vaya expandiéndose por los hogares, como ya sucede en el caso de algunas élites en los países más desarrollados. A partir de ese momento cabrá hablar de una sociedad abierta en el sentido de Popper, puesto que para êl:

"la gran revolución espiritual que condujo al derrumbe del tribalismo y al advenimiento de la democracia no fue sino la emancipación del individuo" 10

En la medida en que las redes telemáticas funcionen como puros soportes para las interrelaciones sociales e individuales, contribuirán a generar un espacio social que se aproxima a la idea que Popper tenía de una sociedad abierta. Sin embargo, no hay que olvidar que Internet está sostenida por instituciones, y no sólo por usuarios individuales. Ello genera problemas adicionales, que conviene analizar, al menos en el caso de la actividad cientifica.

\footnotetext{
. Ibid., pp. 6-7.

${ }^{10}$. Popper, $S A$, p. 107.
} 


\section{3.- La ciencia a distancia.}

La emergencia de la nueva forma de interrelación humana a la que denomino Telépolis ha modificado profundamente la actividad científica, sobre todo a través de las redes telemáticas. La red Internet estuvo dedicada durante muchos años al uso exclusivo en los ámbitos educativos y de investigación ${ }^{11}$, aunque en la actualidad la mitad de los usuarios de dicha red son compañías comerciales y de negocios. Aun así, una de las principales redes soporte de Internet sigue estando patrocinada por la National Science Foundation norteamericana (la NSFNET) y la inmensa mayoría de los científicos de todo el mundo la utilizan habitualmente. Cabe decir, por consiguiente, que Internet es el medio por excelencia para la actividad cientifica intemacional. Mediante el servicio de transferencia de ficheros $(F T P)$, que es el más utilizado en Internet, es posible acceder a programas de ordenador de dominio público, a bases de datos y a las publicaciones científicas que tengan soporte informático, que tienden a ser la mayoría.

La producción científica se ha modificado radicalmente por efecto de esta telematización. Suele hablarse mucho de las universidades a distancia y de las teleconferencias, y sin duda son ejemplos de esta transformación. Sin embargo, las mayores modificaciones han tenido lugar en el contexto de investigación y de innovación tecnocientífica. Hoy en día, la investigacion es una actividad que tiende a realizarse a distancia, tanto por parte de las personas que forman parte de un equipo investigador como, sobre todo, por lo que respecta a la relación entre los científicos que investigan, los aparatos que utilizan y los objetos de investigación.

Desde que las redes telemáticas aparecieron, los cientificos pudieron comunicarse sus trabajos y sus descubrimientos sin necesidad de juntarse en un mismo espacio físico. Los laboratorios dejaron de ser el escenario científico por antonomasia y los diversos aparatos e investigadores pasaron a estar diseminados por distintas zonas geográficas. A partir del

\footnotetext{
11. La primera red telemática fue Arpanet, creada en 1969 para su utilización por las universidades, el Departamento de Defensa y las instituciones y empresas militares de los USA. En 1983 la red Arpanet se dedicó a usos exclusivamente universitarios y de investigación científica, surgiendo la red Milnet para usos militares.
} 
momento en que los servicios de acceso remoto fueron operativos ${ }^{12}$, las posibilidades de interrelación a distancia aumentaron considerablemente. Ya no sólo era posible intercambiar conocimientos, ideas y datos, sino también instrumentos. Consiguientemente, se modificó el modo de producción científica, porque la investigación de los diversos fenómenos dejó de exigir la presencia física del investigador o de los aparatos de observación y de medida.

La tecnociencia se caracteriza por su estricta dependencia de los instrumentos tecnológicos que permiten la observación y la medida de los fenómenos. Muchos de esos instrumentos, como por ejemplo las sondas espaciales y los satélites meteorólogicos, transmiten esos datos a miles de kilómetros de distancia. Contrariamente a lo que propugnaron Russell y algunos miembros del Círculo de Viena, el conocimiento científico no se basa en un conocimiento directo de los objetos (knowledge by acquaintance), sino en un conocimiento mediatizado ${ }^{13}$. Lo esencial es acceder a los datos, y para ello no se requiere estar allí, sino estar conectado telemáticamente al ordenador que los almacena y los procesa ${ }^{14}$. Un investigador que vive en una parte del planeta puede ocuparse de estudiar determinados aspectos del fenómeno, otros se encargarán de otras facetas. La interconexión fiable entre dichos investigadores es una condición indispensable para que avance la investigación. La fiabilidad de las redes telemáticas en la transmisión es una condición previa de la práctica

\footnotetext{
12. Actualmente a través de la red Telnet.

${ }^{13}$. B. Russell escribió en 1914 que "cuando se da un objeto en mi experiencia presente, tengo del mismo un conocimiento directo" ("Sobre la naturaleza del conocimiento directo", en Logica y Conocimiento, Madrid, Taurus, 1966, p. 235). Contrariamente a estas concepciones empiristas, hay que afirmar que los objetos que investigan los cientificos siempre son signos: el conocimiento científico siempre está mediatizado por sistemas de signos, instrumentos, representaciones, etc. Para las concepciones de Camap sobre la "observación directa", véase Testability and Meaning, New Haven, Whitlock's, 1950.

${ }^{14}$. D. Shapere definió la noción de 'directamente observable' de la manera siguiente: " $x$ es directamente observado (observable) si: 1) Se recibe información (o puede recibirse) por medio de un receptor apropiado; y 2) esa información es (o puede ser) transmitida directamente, es decir sin interferencia, desde la entidad x (que es la fuente de la información), hasta el receptor" ("El concepto de observación", en L. Olivé y A.R. Pérez Ranzanz (eds.), Teoría y observación, México, Siglo XXI, 1989, p. 488). La transmisión de los datos a través de las redes telemáticas reitera el problema de la ausencia de interferencia a través del medio de transmisión de información, que no tiene lugar entre objeto y sujeto, sino entre diferentes instrumentos telemáticos.
} 
cientufica. En la medida en que garanticen una comunicación sin ruido, la investigación científica puede llevarse a cabo.

Pensemos en el ejemplo de los cosmologos. Un físico térico puede disponer desde su despacho de trabajo de la representación empírica actualmente vigente del cosmos, que no es otra que los datos informatizados transmitidos por las sondas espaciales. A partir de esos datos, y siempre en función de su conocimiento previo de la materia, elaborará sus propias representaciones mentales, concebirá teorias, propondrá hipótesis y sugerirá experimentos para comprobarlas o refutarlas. Dichos experimentos serán realizados en cualquier parte del mundo: lo importante es que los resultados lleguen a su estancia telemática en forma de datos informatizados fiables. La tecnociencia está mediatizada de principio a fin por la tecnologización de los hechos, cuya representación científica puede estar almacenada en diversos ordenadores dispersos por todo el mundo. El conocimiento que tienen los científicos de los hechos es el conocimiento de unos datos social y tecnológicamente mediatizados. La actividad científica es una interacción reticular, siendo los nodos de esa red las personas y los aparatos que permiten almacenar datos considerados como fiables y generar nuevos datos.

La ciencia actual depende estrictamente de este esquema de investigación a distancia, por lo cual podría hablarse perfectamente de una teleciencia. Si recibe autorización para ello, un investigador de una universidad con escasa infraestructura para la investigación puede utilizar los medios de investigación de una universidad ubicada al otro lado del océano y proceder como si estuviera alli. La investigación científica se vuelve ubicua, sin perjuicio de que haya que pasar por diversas mediaciones personales $\mathrm{e}$ institucionales para poder hacer realidad esas potencialidades.

La ciencia, por otra parte, no es sólo transmisión y producción de conocimiento. Los científicos también desarrollan múltiples actividades institucionales y profesionales. Sigue habiendo simposios, congresos y reuniones científicas. Sin embargo, este tipo de encuentros se han convertido sobre todo en reuniones de negocios, más que auténticos escenarios de la investigación científica. Así como las presentaciones de las nuevas teorías y descubrimientos en las Academias y Sociedades 
Científicas de los siglos XVIII y XIX eran acontecimientos fundamentales dentro del contexto de descubrimiento e innovación, en la actualidad el trabajo más especificamente científico no tiene lugar allí, por muy indispensables que resulten esas reuniones para el buen funcionamiento de las comunidades científicas y para la buena o mala recepción de las innovaciones cientificas que se propongan. Incluso en este caso, un simposio científico o una reunión de un equipo investigador pueden celebrarse sin copresencia física, a través de las redes telemáticas. Sin embargo, las teleconferencias científicas no tienen un interés especial, debido a que la interacción a distancia ya se ha producido antes, cuando se estaba en pleno esfuerzo investigador.

En resumen: la aparición de Telépolis ha traído consigo una profunda transformación del modo de producción del conocimiento científico y del modo de actuación de los científicos. Hoy en día no se puede suscribir la afirmación de Karin Knorr Cetina (y de otros sociólogos del conocimiento científico): "¿dónde hallamos el proceso de validación, en un grado significativo, si no es en el propio laboratorio?" 15 . Contrariamente a esta hipervaloración del laboratorio como escenario donde analizar la investigación cientifica, hay que tener en cuenta que la propia noción de laboratorio se ha modificado considerablemente en las últimas décadas y que los flujos de datos, escritos, hipótesis, críticas y valoraciones a través de las redes telemáticas se están convirtiendo en el referente principal para los historiadores, sociólogos y filosofos de la ciencia que se ocupen de estudiar la ciencia contemporánea.

Los procesos de consenso entre científicos ya no tienen lugar en los laboratorios, sino a través de la intercomunicación telemática, que ha pasado a ser el principal ámbito donde se desarrolla y se objetiva la investigación científica. Las publicaciones que se hacen sobre formato papel, que tradicionalmente habian sido la expresión por antonomasia del conocimiento científico, desempeñan ahora una simple función de archivo. La investigación científica puntera dispone de formatos y de estructuras telemáticas alternativas, que son las que utiliza con preferencia. Una vez que la comunidad científica ha interactuado entre sí y ha

15. K. Knorr Cetina, The Manufacture of Knowledge, Oxford, Pergamon, 1981,8. 
evaluado favorablemente una aportación concreta, ésta pasa a formato impreso. Pero para entonces la investigación ya se está ocupando de otras cuestiones, porque las anteriores han sido resueltas en la estancia telemática que todo científico tiene en su casa o en su despacho en la Universidad correspondiente.

Podemos concluir, por tanto, que la investigación cientúfica ya no tiene lugar en un espacio cerrado (gabinete, laboratorio, estudio, etc.), sino en un ámbito abierto y diseminado, en el que los investigadores y sus instrumentos interactúan a distancia. Al igual que otras muchas actividades profesionales, la práctica científica está sufriendo importantes modificaciones en las últimas décadas.

\section{4.- Las instituciones cientificas en la sociedad abierta.}

El pensamiento de Popper sobre las instituciones en general, y sobre las instituciones científicas en particular, se centra en su propuesta de una ingeniería social fragmentaria, que él contrapuso a la ingeniería utópica de los historicistas:

"La ingenierra social fragmentaria se parece a la ingenierfa física en que considera que los fines están fuera del campo de la tecnología. (Todo lo que la tecnología puede decir sobre fines es si son compatibles entre sí o realizables). En esto difiere del historicismo, que considera los fines de las actividades humanas como dependientes de las fuerzas históricas y, por tanto, dentro de su campo. De la misma manera que la tarea principal del ingeniero físico consiste en proyectar máquinas y remodelarlas y ponerlas en funcionamiento, la tarea del ingeniero social fragmentario consiste en proyectar instituciones sociales y reconstruir y manejar aquellas que ya existen" ${ }^{16}$.

El representante principal de esa ingeniería utópica u holista es, según Popper, Karl Mannheim. Contrariamente a lo que muchos sociólogos de la ciencia suelen afirmar en los últimos años, Popper tuvo muy claro que

${ }^{16}$. Popper, $M H$, pp. 78-79. 
la ciencia es una actividad social, e incluso llegó a reprochar a los sociólogos del conocimiento, y en concreto a Mannheim, que no tuvieran en cuenta la intersubjetividad propia del conocimiento científico:

"Es interesante que lo que normalmente se llama objetividad cientifica se basa, hasta cierto punto, en instituciones sociales. La ingenua opinión de que la objetividad científica se basa en la actitud mental o psicológica del hombre de ciencia individual, en su educación, cuidado y desinterés científico, genera como reacción la opinión escéptica de que los hombres de ciencia no pueden nunca ser objetivos" ... "Esta doctrina, desarrollada con todo detalle por la llamada "Sociología del Conocimiento", olvida enteramente el carácter social o institucional del conocimiento científico, porque se basa en la ingenua opinión de que la objetividad depende de la psicología del hombre individual" ... "Lo que la sociología del conocimiento olvida es precisamente la sociología del conocimiento, el carácter social o público de la ciencia. Olvida el hecho de que es el carácter público de la ciencia y de sus instituciones el que impone una disciplina mental sobre el hombre de ciencia individual y el que salvaguarda la objetividad de la ciencia y su tradición de discutir críticamente las nuevas ideas" ${ }^{17}$.

Popper siempre afirmó que la ciencia es objetiva porque es intersubjetiva. Si tenemos en cuenta que la intersubjetividad está adoptando nuevas formas debido a la expansión de las relaciones humanas a distancia, habremos de comenzar a indagar la existencia de grupos investigadores, e incluso de instituciones científicas de nuevo cuño. Una persona que investiga en una determinada Universidad puede estar trabajando en cuestiones ajenas a las que ocupan a sus colegas de Departamento, y sin embargo puede estar perfectamente interrelacionado con otros expertos en la materia, situados a mucha distancia geográfica. Y lo que es más importante: esa actividad investigadora puede ser abierta. Un grupo de cientificos puede admitir espectadores e incluso participantes activos en

17. Popper, $M H$, pp. 170-71. 
un experimento que comenten a distancia los datos, los resultados y los pasos que se van dando a lo largo de la experimentación. Frente al grupo de investigación cerrado y más o menos tribalizado, que sólo piensa en patentar y privatizar sus innovaciones, las redes telemáticas permiten la emergencia de un nuevo tipo de práctica cientifica, en la que se retoman las grandes presentaciones públicas propias de la ciencia barroca y el principio de difusión universal del conocimiento científico.

Todo ello da lugar a la aparición de nuevas formas de retórica en el discurso científico. Hoy en día resulta esencial un dominio de las artes de simulación y de visualización científica, como queda claro en el caso de los cosmólogos. En la medida en que el discurso de los cientúficos está dirigido a interlocutores situados a distancia, y puesto que el medio de interconexión son las redes telemáticas, el dominio de las artes argumentativas basadas en las imágenes y en las representaciones comienza a ser cada vez más importante. Las técnicas de visualización científica son medios "de exploración de datos y de informaciones" ${ }^{18}$, motivo por el cual se convierten en instrumentos heurísticos relevantes. Así como la percepción era el criterio básico para valorar cientificamente los hechos, la ciencia actual recurre a la percepción de imágenes artificialmente construídas que desempeñan la función de ser representaciones 0 simulaciones de los hechos empíricos. La visualización cientifica no se reduce a una pura técnica de presentación: mediante dichas técnicas, que habitualmente son puestas en práctica a distancia, se trata sobre todo de "entender los datos" ${ }^{19}$. La confrontación entre los científicos y sus objetos de investigación no sólo tiene lugar a distancia: las representaciones de los objetos cientificos constituyen por sí mismas una fase de la investigación, de tal manera que proponer una u otra imagen puede ser decisivo a la hora de convencer al interlocutor del interés de las propias hipotesis.

Jean-Marc Lévy Leblond ha sintetizado esta transformación de la actividad científica de la manera siguiente:

\footnotetext{
18. R. A. Eamshaw y N. Wiseman, An Introductory Guide to Scientific Visualization, Berlín. Springer-Verlag, 1992, p. 5.

19. Ibid.
} 
"Uno de los efectos inducidos por la utilización de los ordenadores en la práctica científica es la desaparición de la vieja dicotomía teoría/experiencia en favor de la estructura tripolar teoría/experiencia/simulación. Eso modifica profundamente la estructura del saber" ${ }^{20}$.

Puesto que los hechos observados están mediatizados por los datos informatizados, y a su vez éstos son presentados en forma de imágenes y visualizaciones artificialmente construídas, el científico se confronta hoy en día con otro tipo de objeto científico, que ya no es el objeto natural percibido por nuestros sentidos, y luego teorizado por nuestra mente, sino un objeto artificialmente construído y telemáticamente transmitido de laboratorio en laboratorio. La transmisión de estas representaciones informatizadas a distancia desempeña un papel cada vez más importante, puesto que equivalen a las antiguas notas, dibujos, esquemas y tablas de datos que los científicos se transmitian de mano en mano en los laboratorios. Así como la investigación científica dependía estrictamente de este tipo de representaciones, así también en la actualidad los científicos se confrontan prioritariamente a representaciones informatizadas. El cambio del medio de expresión y de transmisión del conocimiento científico trae consigo importantes cambios en la práctica y en la producción del conocimiento científico.

Si volvemos a las tesis de Popper sobre las instituciones científicas y a su reactualización en el contexto de Internet, conviene subrayar que el federalismo y la relativa autonomía de las redes telemáticas se corresponde bien con la ingeniería fragmentaria y parcial propuesta por Popper. En lugar de intentar crear una red planetaria perfectamente organizada, y a partir de ello organizar la actividad científica en todo el mundo, como hubieran hecho los ingenieros sociales utopistas, el desarrollo de Internet y la adaptación de los científicos a este nuevo escenario de actuación han seguido una estrategia estrictamente fragmentaria: han surgido redes restringidas dedicadas a temas y a debates concretos, que posteriormente se han ido vinculando con otras redes. Conforme a lo afirmado por Popper:

20. J.M. Lévy-Leblond, Mettre la science en culture, Nice, Anais, 1986, p. 25. 
"los planes de que se sirve el ingeniero gradualista son relativamente simples. En efecto, éstos se refieren a instituciones aisladas" ${ }^{21}$,

así también las nuevas instituciones científicas, que no son otras que las redes específicas integradas en Internet, han procurado corregir y mejorar las instituciones previamente existentes, que frecuentemente estaban lastradas por su caracter local o nacional.

Interpretada desde este punto de vista, al emergencia de Telépolis, y en particular su incidencia sobre la tecnociencia por medio de las redes telemáticas, puede considerarse como un avance hacia una sociedad abierta popperiana precisamente porque en su construcción se han seguido los principios de la ingenieria social fragmentaria, consistentes en actuar institución por institución, y no sobre la globalidad de la sociedad. En la medida en que cada grupo investigador y cada sociedad cientifica ha ido estableciendo sus propias redes telemáticas con el fin de ampliar sus posibilidades de intercambio de conocimientos y de búsqueda de nuevos conocimientos, la teleciencia ha supuesto una neta apertura en relación al gremialismo y al nacionalismo que ha imperado en muchas comunidades científicas a partir de la consolidación de la profesión cientifica. Acaso por ello pueda suscribirse ahora la tesis general de Popper:

"la transición de la sociedad cerrada a la abierta podría definirse como una de las más profundas revoluciones experimentadas por la humanidad" 22.

En el caso de la actividad científica hay que señalar que la aparición de instituciones científicas abiertas, gracias a la implantación de las redes telemáticas como medio de interacción entre las comunidades cientificas, ha traído consigo una profunda transformación de la actividad científica. Ello no equivale a decir que no haya habido tendencias en la dirección

\footnotetext{
${ }^{21}$. K.R. Popper, SA, p. 159.

22. lbid., p. 173.
} 
opuesta: otras muchas instituciones científicas han optado por el secreto y por la privatización como reglas estrictas de comportamiento colectivo. Podemos concluir, por consiguiente, diciendo que la distinción popperiana entre sociedades cerradas y abiertas sigue vigente, y que puede aplicarse de manera muy ilustrativa a las instituciones científicas, y en concreto a su adaptación a la nueva forma de organización social a la que llamamos Telépolis. 